\title{
The Fabrication of Facts:
}

\section{Toward a Microsociology of Scientific Knowledge}

\section{Karin Knorr- Ceiina}

My lord, facts are like cows, if you look them in the face hard enough, they generally run tuvay,

$\sim$ Dorothy I, Sayers

\section{Facts and Fabrication}

Dorothy Sayers's analogy between cows and facts hides both a philosophical and a methodological point. Since both will guide us throughout this essay, I will begin by discussing each at some length. The philosophical point is that facts are not something we can take for granted or think of as the solid rock upon which knowledge $h$ built. Their nature is problematic - so much so that confrontation often scares them off. The methodological point is that the confrontation has to be long, hard, and direct, like cows, facts have become sufficiently domesticated to deal with run-of-the-mill events.

That facts are problematic has been known to philosophers for some time. The quest for the nature of facts.......the core of the quest for the nature of knowledge - is a major reason for the proliferation of epislemological theories. The key dispute is where to locate the problem and how to approach it. Kant, for example, saw the quest as a search for the conditions of possibility of pure science, and found his answer in the categorical make-up of the human, mind.

Recent theories of knowledge have tended to trannsfer the problem from a knowing subject's constitution of the factual to a variety of other locations. Most influential, perhaps, is the shift toward the logic of scientific inference advocated by what some have called objectivism. ${ }^{2}$ To the objecUvlst, the world is composed of facts and the goal of knowledge is to provide a literal account of what the world is like. The empirical laws and theoretical propositions of science are designed to provide those literal descriptions. ${ }^{3}$ If the knowledge of scientific accounts is reality represented by science, an inquiry into the nature of the real becomes an investigation of 
how the logic of scientific accounts preserves the lawlike structure of the real. $^{3}$

Can we say. then, thai the problem of facticity is to be located in the correspondence between the products of science and the external world, and that the solution is to be found in the descriptive adequacy of scientific procedure? There is more than one negative answer to such a proposal. To begin with, while objectivism (in accordance with Marx) stresses the constraints (here identified with nature) which limit the products of science, it is itself oblivious to the constituted character of these products. Peirce has made it the point of his work to argue that the process of scientific inquiry ignored by objectivism (its "context of discovery") is itself the system of reference which makes the objectification of reality possible." The problem of facticity is as much a problem of the constitution of the world through the logic of scientific procedure as it is one of explanation and validation. While the work of Bohm, Hanson, Kuhn, and Feycrabend may not have resulted in a satisfactory model of scientific success, it is generally credited with pointing to the meaning variance or theory dependence of scientific observation.'

Objectivism has been criticized within its own ranks for assuming a factual world structured in a lawlike manner by the constant conjunction of events. According to this critique, constant conjunctions of events result from laboratory work which creates closed systems in which unambiguous results are possible and repeatable. In practice, such constant conjunctions arc exceptions - as is predictive success." The laws proposed by science arc transfactua! and rulelikc, rather than descriptively adequate. The practical success of science depends more on the scientist's ability to analyze a situation as a whole, to think on several different levels at once, recognize clues, and piece together separate bits of information, than on the laws themselves.

Equally relevant is that models of success which do not require the basic assumptions of objectivism are both thinkable and plausible, and have been proposed within the sciences themselves. Psychiatrists, for example, have often used behavioral therapy to successfully treat both major and minor psychic disorders for which they claim not to have nor need any descriptively adequate explanation. A better illustration, perhaps, is the mouse that runs from the cat. ${ }^{7}$ Must we assume that the mouse runs because it has in its mind a correct representation of the natural enmity inherent in the cat? Is it not more plausible to say that any species which fails to run from its natural enemies will cease to exist, which leaves us only with those that did run? Like the progress of evolution itself, the progress of science can be linked to mechanisms which do not assume that knowledge mimics nature.
The critique of empirical realism adds another aspect to the constitutive role which both pragmatism and skepticism attribute to scientific investigation - that the experimenter is a causal agent of the sequence of events created and that conjunctions of events are not provided for us but created by us. The purpose of the present study is to explore how those constant conjunctions are created in the laboratory (suspending for the moment any assumptions about the vocabulary of nature). Rather than view empirical observation as questions put to nature in a language it "understands," we will take all references to the "constitutive" role of science seriously and regard scientific inquiry as a process of production. Rather than consider scientific products as somehow capturing what is, we will consider them as selectively carved out, transformed and constructed from whatever is. And rather than examine the external relations between science and the "nature" we are told it describes, we will look at those internal affairs of the scientific enterprise which we take to be constructive.

The etymology of the word fact reveals it as "that which has been made," in accord with its root in the Latinfacere. to make." Yet we tend to think of scientific facts as given entities, not fabrications. In the present study, the problem of facticity is seen as a problem of (laboratory) fabrications. This means that knowledge is understood in terms of the social process of production which leads to knowledge claims, a process which can be empirically analyzed and specified. Clearly, then, we step beyond philosophical theories of knowledge and their objectivist (or antiobjectivist) concerns. But I would argue that once we sec scientific products as first and foremost the result of a process of construction, we can begin to substitute for those concerns, as some have suggested, an empirical theory of knowledge.?

\section{'The Construetivist Interpretation: Nature and the Laboratory}

How do we defend the contention that scientific inquiry ought to be viewed as constructive rather than descriptive? And what exactly do we mean by this particular qualification? The first question can be answered simply. Even the briefest participafion in the world of scientific investigation suggests that the language of truth and hypothesis testing (and with it, the descriptivist model of inquiry) is ill-equipped to deal with laboratory work. Where in the laboratory, for example, do we find the "nature" or "reality" so critical to the descriptivist interpretation? Most of the reality with which scientists deal is highly preconstructed, if not wholly arlifi- cial.

What is a laboratory? A local accumulation of instruments and devices within a working space composed of chairs and tables. Drawers full 
of minor utensils, shelves loaded with chemicals and glassware. Refrigerators and freezers stuffed with carefully labelled samples and source materials: buffer solutions and finely ground alfa-alfa leaves, single cell proteins, blood samples from the assay rats and lyso/.ymes. $\mathrm{AH}$ source materials have been specially grown and selectively bred. Most of the substances and chemicals are purified and have been obtained from the industry which serves science or from other laboratories. But whether bought or prepared by the scientists themselves, these substances are no less the product of human effort than the measurement devices or the papers on the desks. Nature is not lo be found in the laboratory, unless it is defined as the product of scientific work.

Nor do we find in the laboratory the quest for truth which is customarily ascribed to science. To be sure, the language of scientists contains innumerable references to what is or is not true. But their usage in no way differs from our own everyday use of the term in a variety of pragmatic and rhetoric functions which do not have much to do with the epistemological concept of truth. If there is a principle which seems to govern laboratory action, it is the scientists' concern with making things "work," which points to a principle of success rather than one of truth. To make things work - to produce results - is not identical with attempting their falsification. Nor is it the concern of the laboratory to produce results irrespective of potential criticism. Scientists guard against later attacks by anticipating and countering critical questions before publication. Scientists' vocabulary of how things work, of why they do or do not work, of steps to take to make them work, docs not reflect some form of naive verificationism. but is a discourse appropriate to the instrumental manufacture of knowledge in the workshop called a "lab." Success in making things work is a much more mundane pursuit than truth, and one which is constantly turned into credits in scientific everyday life via publication. Thus, success in making things work is reinforced as a concrete and feasible goal of scientific action, not the distant ideal of truth never quite attained.

"Truth" and "nature" are not the only casualties of the laboratory; the observer would find it equally difficult to locate those "theories" which are so often associated with science. Theories adopt a peculiarly "atheoreticar character in the laboratory. They hide behind partial interpretations of "what happens" and "what is the case," and disguise themselves as temporary answers to "how-to-make-sense-of-it" questions. What makes laboratory theories so atheoretical is the lack of any divorce from instrumental manipulation. They confront us as discursively crystallized experimental operations, and arc in turn woven into the process of performing experimentation.
In place of the familiar alienation between theory and practice, we find an action-cognition mesh to which the received notion of a theory can no longer be adequately applied. According to the scientists themselves, theories in research are more akin to policies than creeds. ${ }^{10}$ Such policies blend interpretation with strategic and tactical calculations, and arc sustained by methodological "how-to-do-it", projections. Like the concern with making things work, policies are necessarily tied to an interest structure. Pure theory can be called an illusion the sciences have retained from philosophy."

The Constructivism Interpretation II: The "Decision Ladenness ${ }^{4_{1}}$ of Fact Fabrication

The inadequacy of those concepts associated with the descriptive interpretation of scientific inquiry is not surprising, given the framework in which they developed. It is no less surprising that a shift in the framework of analysis to the process of research brings new conceptions into being. We have said that this process should be seen as constructive rather than descriptive. Let us be more specific. The thesis under consideration is that the products of science are contextually specific constructions which bear the mark of the situational contingency and interest structure of the process by which they are generated, and which cannot be adequately understood without an analysis of their construction. This means that what happens in the process of construction is not irrelevant to the products we obtain. It also means that the products of science have lo be seen as highly internally structured through the process of production, independent of the question of their external structuring through some match or mismatch with reality.

How can we conceive of this internal structuring of scientific products? Scientific results, including empirical data, have been characterized as first and foremost the result of a process of fabrication. Processes of fabrication involve chains of decisions and negotiations through which their outcomes are derived. Phrased differently, they require that selections be made. Selections, in turn, can only be made on the basis of previous selections: they are based on translations into further selections.

Consider a scientist sitting at an electronic table calculator and running a regression program on texture measurement data. The machine automatically selects a function along which it plots the data. But to choose among the eight functions at its disposal, it needs a criterion. Such criteria are nothing more than second order selections: they represent a choice among other potential criteria into which a first order selection can be translated. In our case, the program actually offered a choice between two 
criteria, maximum $\mathrm{R}^{2}$ and minimum maximum absolute residuum. The scientist had opted for a combination of the two

He obtains an exponential function for his data, which he says he does not like. He reruns the program, asking for a linear function, which he finds to be "not.much worse" (than the exponential one). The idea, he says, is to get one type of equation, and eventually one size Beta coefficient for all runs of the problem, because it would be totally confusing to have different functions in every single case.

From observing the scientist, we might also conclude that the goal must have been to get a linear function. To reach a decision, the original task of the program was to select a function translated into the selection between one of two forms of the statistical fit of the curves, in a stepwisc procedure, the scientist added translations into other criteria, such as uniformity over comparable data and linearity. He eventually chose the latter because it offered greater ease of interpretation and presentation.

In the present case, this kind of translation is seen as an inherent feature of decision making, or - to borrow an expression from Luhrnann of selectivity in general." It allows us to see scientific products as internally constructed, not only with respect to the composite laboratory selections which give rise to the product, but also with respect to the translations incorporated within those selections."

The scientific product can be seen as structured in terms of several orders or levels of selectivity. This complexity of scientific constructions with regard to the selections they incorporate is interesting because it suggests that scientific products are unlikely to be reproduced in the same way under different circumstances. If a scientific product is characterized by several levels of selection (or constellations of selections), it seems highly improbable that the process could be repeated, unless most of the selections are cither fixed or made in a similar fashion.

Given that scientists working on a problem are related through communication, competition, and cooperation, and often share similar educations, instruments, and interest structures, the latter situation is not unusual. But this translation of selections not only points to scientific products as complex constructions incorporating layers of selectivity, but also (as we shall see) provides the threads with which laboratory selections and the products they compose arc woven into the relevant contexts of research.

To reach some form of closure, selections are translated into other selections. To break up that closure, selections can be challenged on their own grounds. Selections can be called into question because they are selections, because they involve the possibility of alternative selections. If scientific objects are selectively carved from reality, they can be deconstructed by challenging the selections they incorporate. If scientific facts are fabricated in the sense that they are derived from decisions, they can be defabricated by imposing alternative decisions. In scientific inquiry the selectivity of what is incorporated into previous scientific work is itself a topic for scientific investigation. Previous selections constitute a resource which enables scientific inquiry to proceed: they supply the tools, methods, and interpretations upon which a scientist may draw in the process of research.

The "artificial" character of the scientist's most important tool, the laboratory, lies in that it is nothing more than a local accumulation of materializations from previous selections. The selections of previous investigations also affect subsequent selections by influencing the conditions of further decision making. The products of science are not only decision-impregnated, they are also decision-impregnating, in the sense that they point to new problems and predispose their solutions.

A scientist's work consists of realizing selectivity within a space constituted by previous selections, and one which is overdeterrnined. In more economic terms, we could say that scientific work requires the reinvestment of previous work in a cycle in which the selections generated by scientific work and their material equivalents are themselves the content and capital of the work. What is reproduced in this cycle is selectivity per sc. This form of autocapitalization in regard to selectivity appears as a precondition for the accumulation of scientific results. It can be multiplied by increasing the number of scientists and financial resources. The conversion of scientific products into research money as described in recent economic models refers to this aspect. ${ }^{14}$ We can also say it refers to scientific productivity rather than to scientific production.

\section{The Laboratory: Context of Discovery or Validation?}

To view scientific investigation as constructive rather than descriptive is to see scientific products as highly internally constructed in terms of the selectivity they incorporate. To study scientific investigation is to study the process by which the respective selections arc made. Does such a study simply shift the focus of analysis from the philosophers' context of justification to that of the generation of ideas? Or from sociologists' realm of consensus formation to the origin of the discoveries about which an opinion is formed? I think not.

Let us begin with the philosopher's contention that validation is in practice a process of rational consensus formation within the scientific community," Since the validators who form this community are presumably independent of the producers of knowledge, their critical judgment constitutes an objective basis of validation. However, if we look at the pro- 
cess of knowledge production in sufficient detail, it turns out that scientists constantly relate their decisions and selections to the expected response of specific members of this community of "validators" or to the dictates of the journal in which they wish to publish. Decisions are based on what is "hot" and what is "out/" on what one "can" or "cannot" do. on whom they will come up against and with whom they will have to associate by making a specific point. The discoveries of the laboratory are made, as part and parcel of their substance, with a view toward potential criticism or acceptance (as well as with respect to potential allies and enemies).

Validations arc made with an eye toward the genesis of the results being validated. Whether a proposed knowledge claim ts judged plausible, interesting, unbelievable, or nonsensical, may depend on who proposed the result, where the work was done, and how it was accomplished. Scientists speak about the motives and interests'* which presumably gave rise to the "finding," about, the material resources available to those who did the research, and about "who stands behind" the results. They virtually identify the results with the circumstances of their generation. The scientific community lends crucial weight to the context of discovery in response to a knowledge claim.

On a more general level, both the producers and cvaluators of knowledge claims are, according to those who favor the distinction between discovery and validation, generally members of the same "community," They are held to share a common stock of knowledge and procedures, and presumably common standards of evaluation, professional preferences, and ways of making a judgment. The validators of a knowledge claim are clients who potentially need a scientific result to promote their own investigations. The selections of previous research become a resource for continuing scientific operations, as well as being a topic of problematization in further research. The validators of a knowledge claim are often the most "dangerous" competitors and antagonists a scientist has in the struggle for credit and scientific authority.

The producers and validators who share methods and approaches, the producers and clients who need each other's services, and the competitors engaged in a struggle for credit or money cannot at the same time be assumed to be independent and, in that sense, objectively critical. Any separation between discovery and validation along these lines is not bome out if we look at scientific practice.

There is a second critique of the separation which should be made clear. We have heard that validation or acceptance, in practice, is seen as a process of consensus formation qualified as "rational" by some philosophers, and "social" by sociologists of science. But whether rational or so- cial, the process appears to be one of opinion formation, and as such, located outside of scientific investigation. Hence, the usual classification of studies of investigation as inquiries into the context of discovery, with little or no concern for problems of validation, leading to the well-known thesis that studies of the production of knowledge in the laboratory are irrelevant to questions of acceptance,

But where do we find the process of validation if not in the laboratory itself?" If not in the process of laboratory decision making by which a previous result, a method or a proposed interpretation, comes to be preferred over others and incorporated into new results? What is the process of acceptance if not one of selective incorporation of previous results into the ongoing process of research production? To call it a process of opinion formation seems to provoke a host of erroneous connotations.

We do not as yet have science courts for official opinion formation with legislative power in the conduct of future research. To view consensus as the aggregate of individual scientific opinions is misleading, since (1) short of regular opinion polls we have no access to the predominant, general, or average opinions of relevant scientists, and (2) it is a commonplace in sociology that opinions have a complex and largely unknown relationship to action. So even if we knew what scientists' opinions were, we would not know which results would be consistently preferred in actual research. What we have, then, is not a process of opinion formation, but one in which certain results arc solidified through continued incorporation into ongoing research. ${ }^{1}$. This means that the locus of solidification is the process of scientific investigation, or in the terms introduced earlier, the selections through which research results are constructed in the laboratory.

\section{The Contextualhy of Laboratory Construction}

Let us dwell for a moment on the idea that to study the process of production of research in the laboratory is to study part of the context of justification, or acceptance. The incorporation of an earlier result into the ongoing process of investigation is seen as a potential step toward solidification. The selection of an available method or interpretation extends its presence (for example, into one more publication) and prolongs its duration. It thereby increases the chances of its further selection and incorporation. An important question, then, is how these selections are made.

Let us first consider what the scientists themselves say when asked such a question. Much as in the case where one scientist evaluates another's work, we are referred to the specific situation in which the decision was made. When we ask. for example, why a particular instrument 
was chosen for a certain purpose, the response may range from "because it is expensive and rare, and 1 want to get to know it," to "it is more economical in terms of energy": from "John suggested it and showed me how to use it," to "it happened to be around, so it was the easiest thing to do" from "what $\mathrm{i}$ had in mind did not work, so I tried something new/" to "they asked me to use this because it has just been bought and we have to show that we needed it": from "it always works, according to my experience," to an astonished stare and the question - "well, what else could you do? $?^{1}$

The few examples above show that these factors have different roots and implications, that they arise from different points in the scientists problematization preceding a decision, and that they correspond to different levels of generality. Taken together, they refer us to the varying situations scientists recall as grounds for their decisions. The existence of an energy crisis, or of the presence of a friend with a suggestion; a failure which triggers a variation in procedure, or a purchase which needs to be justified: a personal "experience" composed of the particulars of a scientific career, or official practice at a given point in time. We cannot hope to reduce these situations to a small number of criteria, much less a principle of rationality, which will allow us henceforth to predict a scientist's laboratory selections. Rather, we will have to take these selections as the product of cooccurrence and interaction of factors whose impact and relevance they happen to constitute at a given time and place, i.e.. the circumstances within which the scientists operate.

Historians have long portrayed scientists' decisions as contingent upon the historical context in which they are situated, and some recent arguments in the philosophy of science also point in this direction." If we take the idea of contextual contingency one step further to suggest that acceptance is a form of environmental selection analogous to the model of biological evolution, we have a plausible alternative to the model of (rational) opinion formation. Like adaptation, acceptance can be seen as the result of contextual pressures which come to bear on scientists' selections in the environmental niches provided by laboratories. If such an interpretation is taken for granted in biological evolution - why is it not an equally plausible characterization of the process of selective "survival" of scientific results? It has the advantage of specifying as potentially relevant the larger social context in which science is embedded and of which scientists' decisions form a part.

But it also has a disadvantage. If we cannot name, once and for all, the criteria according to which scientific results are chosen or eliminated, we are unable to say which selections scientists are most likely to make. ${ }^{50}$ If the context of selection varies over time and place and as a function of previous selections, the rationale for scientific selections will likewise vary. If we add to these variable contextures the chance interactions of circumstantial variables from which selections crystallize, we cannot hope to arrive at generally valid observations about these crystallizations. We are left with the disheartening picture of an indeterminate contextual variation and a social scientist who cannot provide any definite specification of it. Those who have advocated this direction in the recent past have been accused of handing science over to the reign of irrationality, and ruling out the idea of directed or progressive scientific change ${ }^{1}$

\section{Contextual Contingency as a Principle of Change}

Yet this indeterminacy need not have such disquieting implications for the social scientist, let alone implications of irrationality in regard to the selections of science. Recent developments in the theory of self-regulating systems (as well as in thermodynamics) suggest the opposite interpretation - that such indeterminacy is a necessary prerequisite for progressive, organized adaptation, and thus for survival and reconstructive change. ${ }^{22}$ The effect of indeterminacy is no longer viewed as purely disruptive as is the "noise" of information theory which prevents correct transmittance of a signal, the "errors" in the genetic code which prevent normal biological replication, or the "perturbations" in a thermodynamic system. Rather, it is seen as the sine qua non for a progressive organization of the system toward increasing complexity, in spite of local error or loss of information.

To expound this thesis, let us look at the example of biological reproduction. We know that an "error" in the transcription of the genetic code is thought to be the cause of mutations. Yet this random event on the (strictly tepetitive) genetic plane can benefit the species by creating a variation better adapted to changing environmental conditions than the original population. The species "reorganizes" itself by integrating a random mutation which has disrupted the orderly pattern of straightforward reduplication

In the language of communication theory (better suited to questions of social organization), the issue can be reformulated following Allan/* Suppose we have a communicative link between two subsystems $A$ and $B$. If there is no error in a message transmitted from $A$ to $B$, then $B$ will be an exact copy of $A$ and the total information of both will be identical to that of $A$. If the number of errors is such that the ambiguity is identical to the amount of information $A$ transmits, this information will be lost to such a degree that we cannot even talk about transmittance. This means that the structure of $B$ is completely independent of that of $A$, and that the total 
information of both corresponds to that of $A$ plus that of $B$. To the degree that the system depends on the communicative link between these subsystems, this total independence will amount to a destruction of the global system. With regard to the amount of information of the global system, the optimum is to have a nonzero transmission of information between $A$ and $B$ and a certain amount of error in this transmission."

What does the claim that a certain amount of indeterminacy is constitutive for progressive self-organization suggest in the case of science? A minimal definition of scientific development seen as directed change would assume that scientific knowledge is progressively reconstructed knowledge based on the integration or elimination of earlier results, and that this reconstruction is a process of complexificalion. Complexification here means that the system is able to construct and reconstruct itself in new ways.

In common terminology, there are two correlates of this process. On the one hand, there is the ability of science to construct "new" information: that is. to produce innovation, On the other hand, science is apparently increasingly able to construct and reconstruct itself in response to challenges by providing solutions to the problem ${ }^{2 *}$ — which is what we mean when we talk about the success of science. Both abilities are aspects of the process of complexification, which in Shannon's sense corresponds to an increase of information. ${ }^{27}$ But without indeterminacy there could be no such increase of information. This indeterminacy seems to be nothing more than the degrees of freedom used by the system for a problem-absorbing reconstruction of itself. It becomes manifest in the observer's inability to specify in detail a small set of criteria or a principle of rationality according to which this reconstruction proceeds.

How does the idea of such a complexity-increasing reconstruction relate to the notion of contextual selection? Systems theory cannot conceive of self-organizing systems without assuming an environment to which a system responds $/ *$ Deprived of this notion of context, the argument introduced here makes no sense. It is the context which orients, through the selections it promotes, the process of reconstruction and development. We have introduced the notion of context here to refer to the fabric of situated variables on which the scientists base their decisions. These variables appear as the constraints upon which the scientists hold their selections to be contingent. and as the constraints they impose through decision-translations in order to reach closure in an essentially open and expanding sequence of events. Without indeterminacy with respect to these constraints, there would be no problem of closure. And without indeterminacy there would be no new constellations of selections.
The Constructivist Interpretation III: Innovation and Selection

I have drawn upon the analogies of systems theory and biological evolution to argue that the constructivist interpretation of scientific inquiry can be plausibly extended into a contextual model of scientific change in which indeterminacy (or contextual contingency and openness of selections) does not run counter to the idea of scientific success. Let us now examine the negative side of those analogies.

The idea of laboratory selections was introduced here as the link between what is normally separated into the process of acceptance and the process of investigation. I have defined investigation as constructive to emphasize the selectivity embodied in scientific results. But the notion of constructivencss not only points to the decision-laden fabrication of scientific products, but also alludes to the products of fabrication as purposefully "new" products. We have said that selectivity is itself instituted in scientific investigation. Previous scientific selections become a resource for further selections, and thus give rise to both a selective solidification and a diversification of scientific products. In biological evolution, the origin of diversification is clearly identified as a mutation. The first difficulty we face is to find the equivalent of such mutations in the process of scientific construction and reconstruction.

Toulmin's model of scientific change is the closest application of the analogy of biological evolution to the process of knowledge production of which I am aware, and he asks us to take it as a literal description/* According to Toulmin, at any given time we have a pool of scientific innovations and an ongoing process of natural selection among those innovations. The former rests with the creative individual scientist, the latter with the community of experts who judge the innovations..$^{0}$ Mutations arc the variants produced by individual innovation, and their number depends on the degree of freedom of design at a particular time. The decisive factor in biological mutations is that they produce chance variations. With Toulmin, the element of chance is located in the frecdom and creativity of the individual scientist.

This location of chance creates a major problem when the biological model is carried over to scientific (or more generally societal) development. In Toulmin's adaptation of the model, special parts of this development - the individual and innovation - are carved out and given over to chance operations. Left unaffected by chance are the actions of the scientific group and the process of selection of innovation. We recognize in this separation the classic distinction between discovery and validation. What is highly questionable is the rationale for such a separation. Why should the individual suffer (or profit) from chance while the group does not? Or 
why is the selection of innovation a process which makes sense and has direction while innovation itself is not?

Moreover, what do we count as innovation? In Toulminis model, the published but not yet accepted products of scientific work constitute the pool of variations. As we have seen, however, these products are themselves the result of a complex process of selection in the laboratory. More specifically, they are the result of a directional process oriented toward the production of the new. or of innovation. This is implied when we say that the diversification of scientific products (or selectivity) is itself instituted in scientific investigation. From the point of view of the individual scientist as well, innovations are the result of intentional, directed work, and not merely chance happenings. It is the scientists' knowledge of what is a problem and what counts as a solution, educated guesses about where to look and what to ignore, and highly selective, expectation-based tinkering with the material that guides them toward an "innovative" result.

Once a resulf has been obtained, the careful selection of a publisher (and therefore an audience), as well as various marketing strategies, can turn a laboratory product into something which may be widely accepted as new. Nor should we forget that scientists select areas of work which have not been covered by previous research; thus their results are almost guaranteed to pass as new. Scientists constantly strive to secure personal access to resources not readily available to others (e.g., highly expensive or otherwise scarce technical instruments), thereby improving their own chances for being "first" with an innovation. In short, there is nothing nondirectional or purely random about the individual scientist's efforts toward innovation.

One consequence of the directed and constructed character of scientific "mutations" is that the scientist's socially defined being can be seen as the result of a process of individuation which consists of the identification of a person with the differential particularities of the work associated with the person's name." In this way, the solidification of previous results through continued laboratory selections can be seen as leading at the same time to an accelerated diversification of scientific knowledge. Note that reference to the resource-character of selections within this accelerated diversification yields a purely formal specification: it says nothing about the substantial properties or degree of usefulness of the results. The substantial translations from which selections emerge will depend on the context in which they are taken. In this sense, "natural selection" becomes contextual reconstruction.

Apart from the purposive, directed character of scientific "mutations" and their consequences (which point more to Lamarck than to Darwin), another aspect of the present conception of research calls such analogies into question. Here laboratory selections arc not linked to individual decision making but arc seen as the outcome of social interaction and negotiation. Consequently, we must reject such equations as that between the individual and innovation on one hand and between the social group and validation on the other. In a trivial sense, we know that most laboratory work in the natural and technological sciences is conducted by groups, not individuals. The far less trivial implication is that both the products (including those considered innovative) and the ideas of the laboratory are social occurrences which emerge from interaction and negotiation with others. Scientific operations can only make sense within a discourse whose crystallization is found in the scriptures (the authoritative writings) of an area, but which is also constituted by the exegeses and symbolic manipulations in the laboratory.

Science has often been tied to the possibility of a special form of discourse, i.e. written communication. For example, llusserl considers writing to be the condition for the possibility of ideal objects, and therefore of scientific concepts." Peirce argues that manifestation does not reveal the presence of an object but the presence of a sign, and reduces the logic of science to scmiology. Derrida reminds us that the very idea of science was born in a certain epoch of writing." Latour and Woolgar have 'recently illustrated the importance of writing in the laboratory." and the sociology of science has long focused on specific aspects of scientists' written communication.

To say that without writing (in Derrida's wide sense of the word), science could not continue to exist is a commonplace. The point is that the communicative foundation of science constitutes the scientists' operations as a form of discursive interaction directed at and sustained by the arguments of others." The indeterminacy which the analogy of biological evolution seeks to locate in the individual origin of innovation is rooted in the interpretive basis and social dynamics of such interaction. This social and symbolic foundation becomes most visible in the concrete negotiations of the laboratory, in the bargaining which marks the highly selective construction and deconstruction of scientific findings and leads to the continuous reconstruction of knowledge.

The social character of such discursive interaction cannot be limited to some separate context of acceptance through group consensus formation, nor can indeterminacy be isolated in individualized innovation. Innovation and acceptance are temporary stabilizations within a process of reconstruction of knowledge that is at base a social process. The origin of indeterminacy lies within the social, with its symbolic and interactional qualities, and not, as Toulmin appears to suggest, outside. The decisions 
which mark scientific products are locally achieved closures of this indeterminacy. It is within their social location that scientific facts can be seen as selectively constructed and reconstructed.

\section{Internal and External Sources of Reconstruction}

The lack of any simple equivalent to chance mutations throws up an analogical stumbling-block - when we consider scientific development as a process of reconstruction of knowledge. The distinction between system and environment also raises difficulties when we consider the rationale for such a progressive reconstruction. For systems theory, progressive reconstruction (or an increase in complexity) is the system's response to a hypcrcomplex environment to which it adapts by increasing its own degree of complexity. More specifically, the internal reconstruction of a system results from a difference in complexity between system and environment.

But in scientific investigation, the accelerated reconstruction of scientific products is itself the issue of work - it is endogenous to scientific production. As we have seen, it results from the purposive and directional effort of scientists oriented toward the production of new information as defined relative to discursive problematizations.

The difficulty remains even if we switch from the notion of environmental adaptation to that of environmental selection, as required by the biological analogy. In Toulmin's model, the distinction between system and environment seems to correspond to the distinction between the internal world of science and the external affairs of a wider social context. Yet the logic of events is reversed: we do not get, first, a science-internal production of variants (innovations) and then a societal selection of those variants best adapted to the social context. According to Toulmin, the production of innovations is influenced by external factors through various channels, whereas their selective survival is regulated by the internal decisions of the scientific community (at least under normal and ideal conditions).

It is absurd, of course, to assume an opposite division of labor in which innovations are internally produced by scientists and externally selected by the nonscientific members of a society. Yet it is not clear why the former distinction, in which selective power is limited to scientists while external influences are limited to the process of research production, should necessarily be more compelling - if for no other reason than that the locus of selection is itself in the laboratory where it cannot be separated from the process of production. Thus, factors which influence the production of new information will also influence the selective solidification of previous information from which the new, to a significant degree, is derived. If the model of an evolutionary development of science emphasizes (correctly, I think) that the content of a pool of cognitive variants at a given point in science is the product of "internal" and "external" factors, it cannot claim simultaneously that the selection of these variants - which occurs largely during the production of the varianUs themselves - is an exclusively internal matter.

The traditional divide between the internal and external docs not adequately distinguish between contexts which are relevant and irrelevant to knowledge production." Neither systems theory nor theories of evolution offer immediate solutions to the problem. The difficulty is not new: we know that social systems do not have unequivocal boundaries, unlike biological organisms. To be sure, institutional and professional criteria of boundary maintenance exist, but their relevance varies with practical questions. For example, legal rules may effectively regulate access to a particular profession by means of criteria like a university degree, but do not suffice to specify the practical procedures of the respective practitioners. Boundary maintenance is itself at stake in social systems: they are at the center of continual debates and redefinitions. Along with individual scientists' everyday distinctions between "we" and "they," or between matters of "science" and matters of something else, there are degrees of freedom involved in these disputes, just as there are in the social scientist's various regenerations of the distinction. Yet I see no reason to assume a priori that the degrees of freedom between one disciplinary speciality and another are necessarily less than the degrees of freedom between scientists who work in a field and nonscientists who represent a social (or political or economic) interest in the field. If we counted their respective interactions and communications and considered the interests invoked in laboratory selections, we would most likely get the opposite impression.

Degrees of freedom as manifest in perceived borderlines must be seen as a function and not a presupposition of the self-organizing process. We cannot start from a particular division between systems like the one between the scientific community and the rest of the social context and then determine their interaction. As direct observation studies of scientific work indicate, the social context of scientific work is both more restricted and extended than the notion of a specialty community suggests. It is more restricted (more local) in that researchers draw upon a variety of variables that are situationally contingent. For example, their decisions may be influenced by measurement instruments which happen to stand around in the laboratory, or by arguments which come up in a technical discussion. The context of scientific work must be defined more broadly than previously suggested in that these variables and arguments arc not, 
in principle, limited to (bounded by) the scientific community. Direct observation of scientific work suggests that laboratory operations arc embedded within transscientific fields of interaction and discourse. Not only scientists, but also administrators, grant agencies, publishers, participate in these fields of discursive interaction. Transscientific fields are not logical classes whose members share specific characteristics. They are constituted by what is transmitted between agents; they come about through actual or potential (discursive) interaction and communication relevant to what happens in the laboratory.

To conclude: 1 submit that scientists' transscientific involvements are the locus in which the decision criteria invoked by laboratory selections arc defined, revised, and negotiated. In other words, the constraints into which laboratory selections translate and the relationships which nourish these constraints refer us to the above-mentioned transscientific fields of symbolic transactions rather than to a scientific field of communities of specialists. To postulate a relationship between scientists' contextual involvements and laboratory selections mediated by decision criteria is not to suggest that we can read off these criteria from specific contextual involvements. Scientists' concrete decision translations arc simply marked by the same kind of indeterminacy characteristic of practical action in general. However, the transscientific connection of inquiry, and, as a consequence, the social relativity of knowledge can be illustrated by means of concrete examples, as some of the microscopic studies of scientific work show." Work within the framework of a newly emerging sociology of scientific knowledge has only just begun. It is the goal of this work to elaborate-the notion of the constructive character of scientific work and of its transscientific connection persuasively and in empirical detail.

\section{Notes}

1. Critical discussion from different perspectives (leading to different conclusions) can be found in Roy Bhaskar, A Realist Theory of Science (Sussex, England: Harvester Press, 1978) and in JUrgen Mabcrmas, Knowledge and Human Interests (Boston: Beacon Press, (97i).pp.67ff

2. This is not a naive statement of the empirical realist's position, although it may sound like one. The naive position would hold that the picture which science gives us of the world is a true one. In contrast, the above statement emphasizes an cpistemic altitude rather than the correspondence of actual results. For a further discussion of this sec B. van Fraasen, The Argument Conceming Scientific Realism (Los Angeles: University of Southern California, 1977), ch, 2, pp. 2ff. Suppe's formulation is that the results of scientific enquiry are generalized descriptions of reality which must be true in order for the theory to be adequate. Cf. Fredcrik Suppc, ed. The Structure of Scientific Theories (Urbana: University of llinois Press, 1974), p. 211

3.Cf. !labermas.p.69.
4. See "The Logic of 1873" for a formulation of Pcirce's program. Charles S. Peirce, Collected Papers, cd. Charles Hartshorne and Paul Weiss (Cambridge, Mass.: Harvard University Press, 1931-35)

5. For example, sec the symposium edited by Suppe on the question of the meaning variance of observation sentences, in particular the introductory chapter by Suppe, pp. 3-24I.

6. Cf. Bhaskar, particularly ch. 2:118 ff, for an exposition of this critique

7. The example is taken from van Fraasen, p. 45 .

8. This has been pointed out to me by Bruno Latour.

9. The observations upon which the present work is based were conducted in 1976-77 at a government-financed research center in Berkeley, Calif. The center does basic and applied research in chemical, physical, microbiological, toxicological, engineering, and economic areas. My observations focused on a research group working on protein generation and re* covery and on the purification, particle structure, texture, assessment of biological value, and application of plant protein research in the area of human nutrition. For $\mathrm{n}$ more detailed description of the work and empirical data involved sec Karin D. Knorr-Cetina. The tailed description of the work and empirical data involved sec Karin D. Knorr-Cetina. The Science (Oxford: Pcrgamon Press, 1981). See also Karin D. Knorr, "Producing and reproducing knowledge: descriptive or constructive?" Social Science Information !6(1977):669-96; id., "Tinkering toward success: prelude to a theory of scientific practice" Theory and Saciety 8(1979):347-76. For a second study releyant here, one of the first based on participant observation of scientists at work, see Bruno Latour and Steve Woolgar, Laboratory Life: The Social Construction of Scientific Facts (Beverly Hills: Sage, 1979). See also the articles collected in the Sociology of Science Yearbook 4 (Knorr. Krohn, and Whitlcy, 1980), most of which are not based on direct observation. Observation studies similar to the above are currently in progress in various areas of science. See Michael Lynch, "Technical work and critical inquiry: investigations in a scientific laboratory," in Social Studies of Science, Special Issue on the Ethnography of Scientific Work (1982); Doug McKegncy, "Inquiry into Inquiry: Local Action and Public Discourse in Wildlife Ecology," Ph.D. dissertation (Burnaby: Simon Frascr University, 1982); Michael Zenzen and Sal Restivo, "The mysterious morphology of inmiscible liquids: a study of scientific practice," Social Science Information, 21(1982):447-73. These studies can be seen as "empirical epistcrnologics" of science. Sec Leo Apostel et a!,, "An empirical investigation of scientific observation" Communicution and Cognition 6(1979):3-36. wo point toward a microsociology of knowledge interested in analyzing the socia process of scientific investigation from a microscopic - instead of a cultural history or philosophical -..- perspective. It is the goal of these studies to address afresh the hoary old puzzles of the social condi'soning of thought (Mannheim) within the domain of our most authoritative and esoteric system of ideas, scientific knowledge.

10. In 1907, the eminent physicist Joseph John Thomson said, "From the point of view of the physicist, a theory of matter is a policy rather than a creed; its object is to connect or coordinate apparently diverse phenomena, and above all to suggest, stimulate, and direct experiment." Joseph John Thomson, The Corpuscular Theory of Matter (London: Archibald Constable, 1907).

11. This is a paraphrase of Habermas, $(1971$, p. 315$)$, whose meaning differs somewhat $\mathrm{fr}^{\mathrm{am}}$ what is intended here.

12. For a comprehensive exposition of Luhmann's systems theory approach, sec Niklas Luhmann, Soziologischt Aufkldrung: Aufsutze zur Theorie soziater Systeme (Oplaten. 
Westdeutscher Verlag. 1971); Niklas Luhmann, Soziologische Aufkldrung, lid. 2. Aufsatze zur Theorie der Gesellschaft (Opladen: Westdeutscher Verlag, 1975).

13. For the concept of translation see Michel Serres, Hermes III: La traduction (Paris: Minuit, 1974); and the illustrations by Michel Gallon, "L'opcration de traduction comme relation symboliquc," in Les incidences des rapports sociaux sur la science* ed. Michel Roqucplo (Paris: CORDES, 1975), pp. 87-105.

14. Sec the quasi-economic model of Pierre Bourdicu, "The specificity of the scientific field and the social conditions of the progress of reason," Social Science Information 14( 1975): 19-47; and the revised version by Latour and Woolgar.

15. Cf. Karl Popper, Conjectures and Refutations (London: Routledgc \& Kcgan Paul, 1963), pp. $216 \mathrm{ff}$.

16. Sec also Derek Phillips, "Epistemology and the sociology of knowledge; the contributions of Mannheim. Mills, and Merlon," Theory and Society I(1974):82ff. Phillips has pointed out that, as a consequence, we have to assume, in opposition to Mills and Morton, that the motives and social position of an inquirer arc indeed relevant for the evaluation s/he gets from fellow scientists.

17. Other areas relevant here are journals and publishers, or contexts in which decisions about the publication of results arc made. Results which are not published or otherwise circulated effectively have a much smaller chance to even enter the process of general validation

18. It is tempting to quote Wittgenstein here: "So sagst $\mathrm{Du}$ also, dass die Übcreinstimmung der Menschen ciuscheidc. was richtig und was falsch ist? - Richtig und falsch 1st, was Menschen sagen; und in der Sprache stimmen die Menschen (ibcrein. Dies ist keinc Obereinslimmung der Mcinungcn, sondern der Lebcnsform." ("So you are saying thai human agreement decides what is true and false? It is what human beings say that is true and false; and they agree in the language they use. That is not agreement in opinions, but in form of life." Sec paragraph 241 of the Philosophical Investigations (trans. G.E.M. Anscombe)

19.1 am referring here to Fcycrabend's contention that the interpretations which scientists choose are relative to a cultural and historical context and can only be understood if we look at these contexts. The thesis rules out the possibility of specifying $a$ sei of context-independent criteria according to which consensus formation proceeds. In contrast, Kuhn docs not rule out the possibility of such criteria. Paul Fcyerabend, Against Method (London: New Left Books, 1975); and Thomas S. Kuhn, The Structure oj Scientific Revolutions (Chicago: University of Chicago Press, 1970), 2nd enlarged ed. (first published 1962), particularly the discussion in the postscript.

20. Note that Toulmin's model of scientific evolution (the closest adaptation of the biological model) goes to some length to avoid such consequences. First, as we shall sec later, Toulmin restricts the idea of environmental selection to a form of scientific selection. Second. as Lakatos points out in his critique of Toulmin, he invokes a "Cunning of Reason" in history which somehow secures the final validity of selections. For these and other reasons which will become clear later, Toulmin's model is not a contextual model as proposed here. Stephen Toulmin, Human. Understanding (Oxford: Clarendon. 1972); Imrc Lakatos, "Understanding Toulmin," Minerva 14( i 976): 126.43.
21. For a summary presentation of the whole discussion, see Inure Lakalos and Alun Musgrave, cds., Criticism and the Growth of Knowledge (Cambridge, England: Cambridge University Press, 1970).

22. In stochastic processes on the molecular level, in which the smaller the number of interacting molecules the greater the role of fluctuation, it has been shown that the absence of "errors" or indeterminacy corresponds not only to an absence of innovation and hence of an increase of information, but to an actual loss of information. Without chance fluctuations, the system cannot maintain itself in a stationary state. This means that without the intervention of "error." chance, or indeterminacy in biological evolution, for example, all species would disappear without being replaced. Cf. Henri Allan, Entre le cristal et la/unite: Essai sur l'organisation du vivant (Paris: Seuil, 1979), p.545. For a propagation of the idea as a principle of order relevant to science sec Latour and Woolgar.

23. Allan's reinterpretation of the problem is crucial because it suggests that the point is not the construction of "order" out of disorder (indeterminacy, chance), but the emergence of organization as defined by an increase in complexity or system differentiation. The original definition envisioned an increase of repetition or redundancy with which the notion of order is associated in information theory.

24. See Atian, p. 47

25. As a simple example, consider the leak in the communicative network of the Nixon administration with regard to the bombing of Cambodia (kept secret by the administration). While the leak was disruptive for some core members of the administration, it may well have benefited the more global system of American democracy. The implication is that we have to take into account different levels of organization to distinguish between the disruptive and intcgrative (or organizing) effects of noise.

26. Of course, science produces new problems at the same time, which is part of the process of reconstruction,

27. The quantity of information within a system is taken to be a measure of the improbability that the combination of the different constituents of the system is the result of chance. This is why the quantity of information could have been proposed as a measure of complexity. Strictly speaking, there are three different versions of writing I he quantity of information (strictly speaking, the

28. According to Ashby, it is logically impossible that a self-organizing system be closed, i.e. a system which docs not interact with an environment. If the syslcm could change its organization solely as a function of its internal states, this change would be governed by a constant. True change has to be induced either through a program of change injected from the outside or through external chance interferences. See W. Ross Ashby, "Principles of the Self-Organizing System," in Principles of Self-Organization ed. H. von Foersier and G.W. Zopf (New York: Pergamon, 1962), pp. 225-78.

29. See Stephen Toulmin. "The evolutionary development of natural science," American Scientist 57( 1967):470. for a short presentation of his model and of the nonmetaphoric reading intended (pp. 470ff.).

30. Toulmin seems to suggest that this is normally and ideally the case. Cf.esp, par. 4 ,

31. Since change and parliculamation are built into scientific products, we can also say that scientific work allows for differentiation effects, and these can be appropriated by scientists. The individuation provided by scientific work need not necessarily go to individual persons. Many would argue that the increasing socialization of science means that we have 
an increasing appropriation of differentiation effects by groups, and more importantly, by institutions.

32. See Edmund Husscrl, "Die Frage nach dem Ursprung der Geometric a Is intentional-historisches Problem." in Husserliana, vol. 6 (The Hague: Nijhoff. 1962),

33. For a short presentation, sec the chapter on "Logic as Scmiotic" in the Dover edition of f'circe's selccted writings. Charles S. Pcirce, Philosophical Writings of Peirce, cd. Justus Buchlcr (New York: Dover, 1955), pp. 98ff. I am referring to Jacques Dcrrida, Of Grammatology (Baltimore: Johns Hopkins University Press, 1976). p. 27.

34. La lour and Woolgar.

35. Bohme has concluded that a concept of the scientific community within a theory of scientific action needs to be based on a thcory of lhe process of argumentation in science. See Gcrnot Böhme, "The Social Function of Cognitve Suwctures: A Concept of the Scientific Community within a Theory of Action," in Determinants and Controls of Scientific Development, ed. Karï D. Knorr, Hermann Strasser, and Hans $\mathrm{G}<$ Zilian (Dordrecht, Holland: D. Rcidel, 1975), pp. 205-26.

36. Cf. Ron Johnston, "Contextual knowledge: a model for the overthrow of the internal/external dichotomy in science," Australia and New Zealand Journal of Sociolog 12(1976): 193-203. Johnston summarizes some of the uses of the internal/external distinction which he traces back to assumptions enshrined in the history and philosophy of science that have been unqueslioningly adopted by subsequent analyses of science.

37. Sec the studics citcd in note $\dot{9}$ which have begun to document this constructivity and contextuality. 